\title{
Extrato de babosa e manjericão na germinação e crescimento inicial de rúcula
}

\section{Extract from aloe vera and basil in germination and initial growth of arugula}

\author{
Amanda do Prado Mattos ${ }^{\text {*; }}$ Bruna Rezer Machado²; Bruna Broti Rissato ${ }^{3}$ Luis Henrique Brambilla \\ Alves $^{4}$
}

${ }^{1}$ Mestrado em Agronomia, Universidade Estadual de Maringá, Maringá, Paraná; (49) 99112-0167, pradomattosa@gmail.com; 2Graduação em Agronomia, Universidade Federal de Santa Catarina, Curitibanos, Santa Catarina, brunarezer@outlook.com; ${ }^{3}$ Doutorado em Agronomia, Universidade Estadual de Maringá, Maringá, Paraná, brunarissato@hotmail.com; ${ }^{4}$ Graduação em Agronomia, Universidade Estadual de Maringá, Maringá, Paraná, luisbrambilla@hotmail.com.

NOT A
CIEN TÍ F I C A

Recebido: $17 / 10 / 2019$

Aprovado: 14/12/2019

Palavras-chave:

Alelopatia

Compostos secundários

Plantas medicinais
Key words:

Allelopathy

Secondary compounds

Medicinal plants

\section{R E S U M O}

Algumas plantas podem produzir compostos secundários com potencial benéfico no manejo agrícola, como alternativa à utilização no tratamento de sementes, porém, podem apresentar algum tipo de alelopatia inibitória ao desenvolvimento de determinadas culturas de interesse. Logo, o objetivo deste trabalho foi avaliar efeitos alelopáticos do extrato aquoso de manjericão (Ocimum basilicum L.) e babosa (Aloe vera L.) em concentrações na germinação e desenvolvimento inicial de sementes de rúcula (Eruca sativa L.). A concentração para o extrato aquoso foi de $20 \%$ (peso/volume) e a partir desta, foram obtidas as demais concentrações. Os tratamentos utilizados foram as concentrações de $25,50,75$ e $100 \%$ dos extratos de babosa e manjericão extraídos pelo método a frio de turbólise, e testemunha com água autoclavada.Os efeitos dos extratos foram avaliados quanto as variáveis: índice de velocidade de germinação, porcentagem de germinação, comprimento de radícula e parte aérea. $\mathrm{O}$ experimento foi conduzido em delineamento inteiramente casualizado, com 6 repetições, sendo a unidade experimental composta por uma caixa gerbox com 50 sementes de rúcula. As doses de manjericão e babosa foram testadas em experimentos distintos. Os extratos de manjericão e de babosa apresentam substâncias que favorecem o desenvolvimento da parte aérea, influenciaram negativamente no desenvolvimento da radícula, porém, não apresentaram efeito alelopático na germinação final e velocidade de germinação de sementes de rúcula.

\begin{abstract}
A B S T R A C T
Some plants may produce secondary compounds with potential beneficial in agricultural management, as an alternative to use in seed treatment however, may present some type of allelophathy inhibitory to the development of certain crops of interest. Therefore, the objective of this work was to evaluate the effects allelopathic of water extract of basil (Ocimum basilicum L.) and aloe (Aloe vera L.) at different concentrations in the germination of the seeds of the arugula (Eruca sativa L.). The concentration for the aqueous extract was $20 \%$ (weight / volume) and from this the other concentrations were obtained. The treatments used were the concentrations of 25, 50, 75 and $100 \%$ of extracts from aloe and basil extracted by the method of cold turbolise, and witness water autoclaved. The effects of the extracts the experiment was conducted in delineation entirely randomed, with 6 repetitions, being the experimental unit composed by a box Gerbox ${ }^{\circledR}$ with 50 seeds of arugula were assessed for the variables: index of speed germination, percentage of germination, length of radicle and aerial part. The extracts of basil and aloe have any substance or an association of secondary compounds with effect allelopathic that favored the development of the aerial part, influenced negatively on development of the radicle, however, showed no effect allelopathyc in the germination of the seeds of the arugula.
\end{abstract}

\section{INTRODUÇÃO}

As plantas apresentam mecanismos de defesa que baseiam-se na síntese de metabólitos secundários que podem

interferir no ciclo de vida de outra planta e de microrganismos. Tal mecanismo é denominado de alelopatia (PIRES; OLIVEIRA, 2011). Os aleloquímicos podem ser liberados ao meio pelas plantas de forma aérea por

\section{Revista Verde}

ISSN 1981-8203

Pombal, Paraíba, Brasil v. 15, n.1, jan.-mar, p.100-104, 2020

doi: 10.18378/rvads.v15i1.7317 
volatilização, por exdudação radicular e lixiviação ou por decomposição de restos culturais (FERREIRA; BORGHETTI, 2004), influenciando, por exemplo, na germinação de sementes e desenvolvimento de plântulas, na utilização de água e assimilação de nutrientes, no crescimento de raízes, na fotossíntese e no controle de pragas e doenças (SILVA et al., 2013; CRUZ-SILVA et al., 2015; FONSECA et al., 2015; PINHEIRO et al., 2016; TONETTE NETO et al., 2018).

As plantas medicinais e aromáticas destacam-se em relação à produção de compostos alelopáticos (fenóis, terpenos, alcalóides, poliacetilenos, ácidos graxos, peptídeos) (ROSADO et al., 2009). A babosa (Aloe vera L.) e o manjericão (Ocimum basilicum L.) são espécies que produzem uma ampla variedade destes compostos, além de apresentarem grande importância econômica (ROSADO et al., 2009; NARIAI et al. 2013). Tais plantas apresentam poder alelopático inibitório a outras espécies, como a alface, o tomate e a cenoura podendo influenciar em fatores como a germinação e o comprimento de radícula e parte aérea (ROSADO et al., 2009; NARIAI et al. 2013; FORMAGIO et al., 2010; MIRANDA et al., 2015).

Os compostos secundários produzidos por determinadas plantas podem possuir potencial benéfico no manejo agrícola, como alternativa à utilização de defensivos como herbicidas, fungicidas, inseticidas e nematicidas, porém, podem apresentar algum tipo de alelopatia inibitória ao desenvolvimento de determinadas culturas de interesse (FERREIRA; AQUILA, 2000; SANTOS et al. 2013).

A busca por alternativas à utilização de defensivos químicos vem crescendo no contexto agrícola, onde os extratos de olerícolas medicinais e aromáticas vem se destacando para essa finalidade. Estes extratos oferecem vantagens em relação aos agroquímicos, como menor toxicidade, rápida degradação no ambiente, derivados de recursos renováveis, amplo modo de ação e ainda, gerar novos compostos que os patógenos não são capazes de inativar (SANTOS et al. 2013).

Estes compostos gerados pelas plantas podem ser utilizados no tratamento de sementes contra pragas e doenças, mas podem vir a causar efeitos inibitórios no desenvolvimento das plantas cultivadas, e assim consequente perda de produtividade (RAZAVI, 2011). Logo, os efeitos gerados por tais aleloquímicos às plantas e microrganismos ao seu redor devem ser estudadas visando a realização de um melhor manejo nos cultivos, principalmente hortícolas, assim como a sua utilização como alternativa na agricultura orgânica à defensivos químicos.

Dentre as hortaliças folhosas, a rúcula vem conquistando maior espaço no mercado brasileiro, sendo uma espécie muito rica em proteínas, sais minerais, vitaminas A e C, cálcio, ferro, além de possuir efeitos anti-inflamatório e desintoxicante para o organismo. Segundo a ABCSEM (2017), foram comercializadas 61 toneladas de sementes de rúcula no país no ano de 2016, com 40.949 ha plantados e crescimento de mercado de $26 \%$ nos últimos 4 anos. Contudo, apesar de sua importância econômica para a horticultura, existem poucos estudos relacionados à influência que a alelopatia do extrato de outras plantas podem causar a cultura (DIJKSTRA et al., 2017).

Dada à importância nutricional e econômica da espécie estudada, maiores informações sobre os fatores que podem influenciar a produção desta devem ser inquiridos. Espécies como manjericão e babosa, além de produzirem muitos compostos secundários e serem de fácil acesso, possuem grande importância econômica podendo ser utilizadas no tratamento de sementes de rúcula, assim como no consórcio com a mesma, caso não apresentem alelopatia inibitória com a cultura em questão.

A partir disso, o objetivo deste trabalho foi avaliar os possíveis efeitos alelopáticos do extrato aquoso de manjericão (Ocimum basilicum L.) e babosa (Aloe vera L.) em concentrações na germinação e crescimento inicial de sementes de rúcula (Eruca sativa L.).

\section{MATERIAL E MÉTODOS}

O experimento foi realizado no Laboratório de Fitopatologia da Universidade Federal de Santa Catarina, Campus Curitibanos. A coleta das folhas das espécies de babosa (Aloe vera L.) e manjericão (Ocimum basilicum L.) foi realizada no final da tarde, em uma horta doméstica de cultivo orgânico $\left(27^{\circ} 17^{\prime} 09.3^{\prime \prime} \mathrm{S} \quad 50^{\circ} 34^{\prime} 33.2^{\prime \prime} \mathrm{W}\right)$, onde o manjericão é conduzido em cultivo protegido. A coleta foi realizada com o auxílio de uma tesoura de poda, e as folhas foram acondicionadas em caixa térmica, até o momento da extração. Após coletadas, as folhas foram desinfestadas em hipoclorito $2 \%$ por 1 minuto e posteriormente em água autoclavada para retirada de resíduos.

O extrato das plantas foi obtido a partir do método a frio de turbólise, onde as folhas frescas foram trituradas juntamente com água destilada autoclavada por 3 minutos, com a utilização do liquidificador industrial. Foram adicionados ao liquidificador $100 \mathrm{~g}$ de folhas da planta e 500 $\mathrm{mL}$ de água destilada autoclavada. A concentração para o extrato aquoso foi de $20 \%$ (peso/volume) (ROSADO et al., 2009; NARIAI et al., 2013) e a partir desta, foram obtidas as demais concentrações de 25, 50 e $75 \%$. Após a trituração, a solução foi filtrada em ambiente asséptico com o auxílio de peneira e gases. O extrato aquoso obtido representa $100 \%$ em concentração. Para obter as demais concentrações, uma alíquota de $25,50,75 \mathrm{~mL}$ do extrato foi coletada e completada a $100 \mathrm{~mL}$ com água autoclavada. $\mathrm{O} \mathrm{pH}$ de todos os extratos foi ajustado para 6,0 .

Foram utilizadas caixas Gerbox e papel germitest ${ }^{\circledR}$ previamente esterilizados. Em cada unidade amostral (caixa gerbox) foi adicionado 3 folhas de papel germitest ${ }^{\circledR}$ e em seguida $10 \mathrm{~mL}$ de extrato aquoso nas concentrações correspondentes (volume em 2,5 vezes o peso do papel). Posteriormente foram adicionadas 50 sementes de rúcula da variedade Cultivada provenientes do comércio local. As caixas gerbox foram acondicionadas em câmara de germinação, com fotoperíodo de $12 \mathrm{~h}$, em temperatura de $20^{\circ} \mathrm{C}$. Os tratamentos utilizados foram às doses de $25,50,75$ e $100 \%$ dos extratos de babosa e manjericão, e testemunha com apenas água destilada autoclavada.

As análises foram feitas diariamente durante sete dias para determinar o índice de velocidade de germinação (IVG), calculado segundo Maguire (1962) (Eq. 1).

$$
\mathrm{IVG}=\Sigma \mathrm{ni} / \mathrm{i}
$$

Em que: ni $=$ número de sementes germinadas por dia; $\mathrm{i}=$ número de dias transcorridos a partir da semeadura.

Aos quatro e sete dias (BRASIL, 2009) as plântulas foram avaliadas, para a determinação da porcentagem de 
germinação pela fórmula $\left(\mathrm{n}^{\mathbf{0}}\right.$ de sementes germinadas $/ \mathrm{n}^{\mathbf{0}}$ de sementes total)x 100 , comprimento de radícula e parte aérea. As radículas e parte aérea foram dimensionadas com auxílio de um paquímetro digital, sendo os resultados expressos em cm plântula ${ }^{-1}$.

Foram realizados dois experimentos, um com as doses de babosa e outro com as doses de manjericão. Estes foram conduzidos em delineamento inteiramente casualizado, com 5 repetições, sendo a unidade experimental composta por uma caixa gerbox com 50 sementes de rúcula. A análise estatística foi realizada no software R (R CORE TEAM, 2019), e a comparação de médias com teste de Tukey, 5\% de probabilidade de erro.

\section{RESULTADOS E DISCUSSÃO}

$\mathrm{Na}$ análise do número de sementes germinadas de rúcula, foi possível averiguar que as doses de extrato de manjericão e de babosa não apresentaram interferência na porcentagem de germinação das sementes tão quanto na velocidade de germinação. A germinação das sementes foi em média de $95 \%$ e o IVG de 25 (Tabela 1 ).

Ferreira e Aquila (2000) explicam que o processo de germinação apresenta baixa sensibilidade aos compostos aleloquímicos em relação a demais características como o desenvolvimento da radícula e parte aérea. Porém, estudos demonstram que o extrato de manjericão apresentou efeito alelopático negativo sobre a germinação de sementes de outras culturas de interesse, como o trigo, bem como de sementes de plantas daninhas, na dose de 5\% (PETROVA et al., 2015). Em relação à babosa, estudos como o de Lorensi et al. (2017) mostram que o extrato de babosa estimulou a velocidade de emergência em $14 \%$ de sementes de tomateiro. Desta forma, observa-se que dependendo das espécies estudadas, o processo de alelopatia relacionado à germinação e IVG pode variar, podendo ser positivo, negativo ou neutro.

Tabela 1. Porcentagem de germinação de sementes e índice de velocidade de germinação (IVG) em doses de extrato de babosa e de manjericão.

\begin{tabular}{ccccc}
\hline Tratamentos & Manjericão & \multicolumn{2}{c}{ Babosa } & IVG \\
\hline Testemunha & Germinação $(\%)$ & IVG & Germinação $(\%)$ & $25.06^{\mathrm{ns}}$ \\
$25 \%$ & $89.0^{\mathrm{ns}}$ & $25.34^{\mathrm{ns}}$ & $95.5^{\mathrm{ns}}$ & $26.12^{\mathrm{ns}}$ \\
$50 \%$ & $96.5^{\mathrm{ns}}$ & $23.87^{\mathrm{ns}}$ & $98.0^{\mathrm{ns}}$ & $27.13^{\mathrm{ns}}$ \\
$75 \%$ & $97.5^{\mathrm{ns}}$ & $26.23^{\mathrm{ns}}$ & $90.0^{\mathrm{ns}}$ & $24.65^{\mathrm{ns}}$ \\
$100 \%$ & $97.0^{\mathrm{ns}}$ & $26.45^{\mathrm{ns}}$ & $94.5^{\mathrm{ns}}$ & $26.41^{\mathrm{ns}}$ \\
\hline CV $(\%)$ & $92.0^{\mathrm{ns}}$ & $26.72^{\mathrm{ns}}$ & $91.0^{\mathrm{ns}}$ & 5.88 \\
\hline
\end{tabular}

ns: médias não diferem entre si pelo Teste de Tukey a 5\% de probabilidade

O extrato de manjericão influenciou negativamente no comprimento da radícula das plântulas de rúcula em todas as doses testadas. A dose de $100 \%(0,94 \mathrm{~cm})$ apresentou maior efeito negativo sobre a radícula, com $58 \%$ de inibição em relação à testemunha $(2,3 \mathrm{~cm})$ (Figura 1a). As doses de 25, 50 e $75 \%$ não diferiram entre si, com média de inibição de crescimento de 35\%. Rosado et al. (2009) averiguaram efeito semelhante nas culturas de alface e melissa, em que extrato aquoso de manjericão apresentou efeito inibitório no comprimento de raízes.

Todavia, o extrato de manjericão agiu positivamente no comprimento da parte aérea das plântulas de rúcula em todas as doses testadas, com média $54 \%$ de incremento em relação à testemunha (Figura 1b). Da mesma forma Dorneles et al. (2015), observou que o extrato de manjericão estimulou o crescimento de plântulas de melão na parte aérea e raiz nas doses de $2 \%$, porém inibiram na dose de $8 \%$.

Figura 1. Comprimento da radícula (a)e parte aérea (b) de plântulas de rúcula com doses de extrato de manjericão

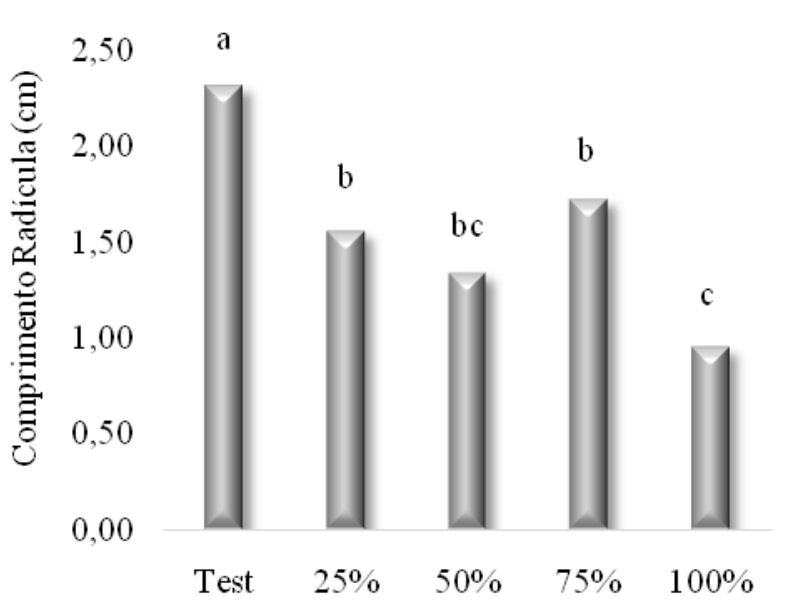

Doses de extrato

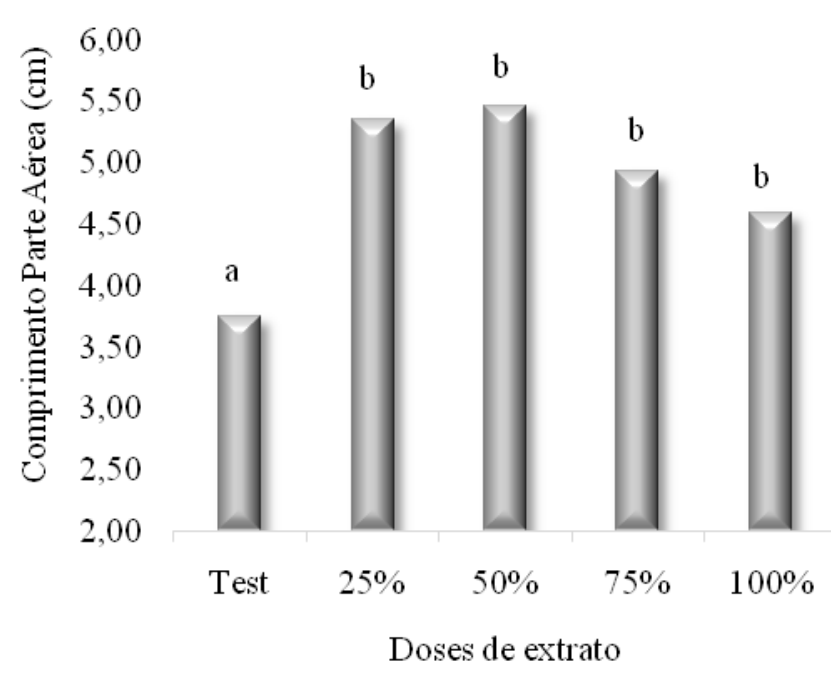

Médias seguidas por letras iguais não diferem entre si pelo Teste de Tukey a 5\% de probabilidade

A espécie Ocimum basilicum L. é rica em monoterpenos e sesquiterpenos (IIJIMA et al., 2004). Rosado et al. (2009), verificaram em análise por GC- MS do óleo de Ocimum basilicum 'Maria Bonita' a presença dos compostos 1,8-cineol, 
linalol, geraniol, $\alpha$-terpineol, acetato de geranila, $\alpha$-transbergamoteno, $\gamma$-cadineno e epi- $\alpha$-cadinol, sendo o linalol e geraniol os componentes majoritários. Logo, pode-se considerar que estes compostos podem estar envolvidos na influência do extrato sobre as plântulas de rúcula.

O extrato de babosa não apresentou influência no comprimento da radícula, onde todas as concentrações foram iguais à testemunha com média de $3 \mathrm{~cm}$. No entanto, apresentou influência no comprimento da parte aérea, havendo um incremento no crescimento nas doses de 50, 75 e $100 \%$ de 49, 28 e $39 \%$ respectivamente (Figura 2).

Nariai et al. (2013), relataram que plântulas de alface crescidas na presença do extrato de babosa tiveram aumento no comprimento da raiz nos extratos de 25 e $50 \%$ e da parte aérea em todos as doses testadas. No presente trabalho, a dose de $25 \%$ não diferiu da testemunha, apresentando média de $3,5 \mathrm{~cm}$, o que demonstra que a sensibilidade de cada cultura é distinta em relação aos compostos alelopáticos. Outra possível justificativa é a diferente concentração de compostos obtidos de diferentes plantas de babosa. Os compostos mais encontrados na babosa e possíveis responsáveis pela alelopatia são o pirocatecol, ácido cinâmico, ácido ascórbico e ácido p-cumárico, que provavelmente atuam de forma sinérgica (FREITAS et al., 2014).

Figura 2. Comprimento da radícula (a) e parte aérea (b) de plântulas de rúcula com doses de extrato de babosa
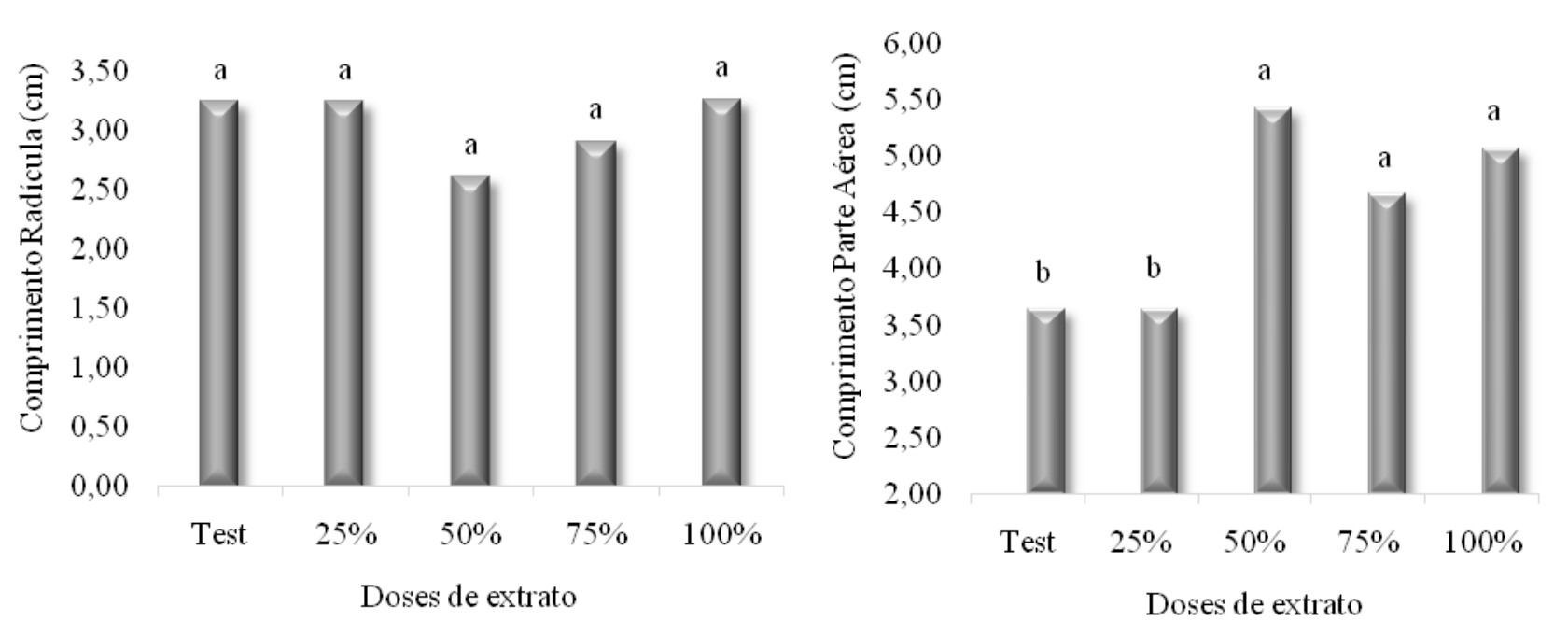

Médias seguidas por letras iguais não diferem entre si pelo Teste de Tukey a 5\% de probabilidade

O estímulo no crescimento de plantas a partir da utilização de extratos vegetais pode ser explicado pela interferência dos aleloquímicos na síntese e ação dos fitormônios, além da presença de compostos como açúcares, aminoácidos e sais no extrato (ROSADO et al., 2009; SILVA et al., 2011; NARIAI et al. 2013; LORENSI et al., 2017). Observa-se então, que a alelopatia não pode ser reduzida aos efeitos deletérios às culturas. A alelopatia também pode ser positiva, onde as plantas vivas ou mortas liberam compostos que podem exercer efeito sobre outras plantas, desempenhando papel fundamental nos ecossistemas naturais e agrícolas (LI et al., 2011).

\section{CONCLUSÃO}

Os extratos de manjericão e de babosa não afetam a porcentagem e velocidade de germinação das sementes e favoreceram o desenvolvimento da parte aérea de plântulas de rúcula. $\mathrm{O}$ extrato de manjericão diminui o seu crescimento da radícula.

\section{REFERÊNCIAS}

ABCSEM. Associação Brasileira do comércio de sementes e mudas. O Mercado de Folhosas: Números e Tendências. 2017. Disponível em: 〈https://www.abcsem.com.br> Acessado em 02 jan. 2019.
BRASIL. Ministério da Agricultura, Pecuária e Abastecimento. Regras para Análise de Sementes / Ministério da Agricultura, Pecuária e Abastecimento. Secretaria de Defesa Agropecuária. - Brasília: Mapa/ACS, 2009. 399 p.

CRUZ-SILVA, C. T. A.; NASU, E. G. C.; PACHECO, F. P.; NOBREGA, L. H. P. Allelopathy of Bidens sulphurea L. Aqueous extracts on lettuce development. Revista Brasileira de Plantas Medicinais, v.17, n. 4, p.679-684, 2015. $\underline{10.1590 / 1983-084 X / 14 \quad 096}$

DIJKSTRA, D. D.; LONGO, U.; GUILHERME, I. H.; FERREIRA, R. V.; DIAS, L. N. S.; BUSO, W. H. D. Cultivo de Eruca sativa sob diferentes manejos nutricionais. Revista Agrarian, v.35, n.10, p. 61-69, 2017. $\underline{10.30612 \text { /agrarian.v10i35.3365 }}$

DORNELES, K. R.; POZZEBON, B. C.; ETHUR, L. Z.; ZEIST, A. R. Efeito alelopático de extratos de plantas medicinais e condimentares em meloeiro (Cucumis melo L.). Ciência e Natura, v. 37, n. 2, p. 212-217, 2015. $\underline{10.5902 / 2179460 \times 14763}$

FERREIRA, A. G.; AQUILA, M. E. A. Alelopatia: uma área emergente da ecofisiologia. Revista Brasileira de Fisiologia Vegetal, v. 12, n. 1, p.175-204, 2000.

FERREIRA, A. G.; BORGHETTI, F. Germinação: do básico ao aplicado. Porto Alegre: Artmed, 2004. 
FONSECA, M. C. M.; LEHNER, M. S.; GONÇALVES, M. G.; PAULA JÚNIOR, T. J.; SILVA, A. F.; BONFIM, F. P. G.; PRADO, A. L. Potential of essential oils from medicinal plants to control plant pathogens. Revista brasileira de plantas medicinais. v.17, n.1, p.45-50, 2015. 10.1590/1983084X/12_170.

FORMAGIO, A. S. N.; MASETTO, T. L. BALDIVIA, D. S.; VIEIRA, M. C.; ZÁRATE, N. A. H.; PEREIRA, Z. V. Potencial alelopático de cinco espécies da família Annonaceae. Revista brasileira de Biociências, v. 8, n. 4, p. 349-354, 2010.

FREITAS, V. S.; RODRIGUES, R. A. F.; GASPI, F. O. G. Propriedades farmacológicas da Aloe vera (L.) Burm. f. Revista brasileira de plantas medicinais, vol.16, n.2, pp.299307. 2014. 10.1590/S1516-05722014000200020

IIJIMA, Y.; DAVIDOVICH-RIKANATI, R.; FRIDMAN, E.; GANG, D. R.; BAR, E.; LEWINSOHN, E.; PICHERSKY, E. The biochemical and molecular basis for the divergent patterns in the biosynthesis of terpenes and phenylpropenes in the peltate glands of three cultivars of basil. Plant Physiol., v.3 pp. 3724-3736, 2004. 10.1104/pp.104.051318

LI, J.; LIU, X.; DONG, F.; XU, J.; LI, Y.; SHAN, W.; ZHENG, Y. Potential allelopathic effects of volatile oils from Descurainia sophia (L.) Webb ex Prantl on wheat. Biochemical Systematics and Ecology, v. 39, n. 1, p. 56-63, 2011. 10.1016/j.bse.2010.12.022

LORENSI, C. A.; PASSAMANI, B. R.; PONCE, M. M.; ETHUR, L. Z. Alelopatia de extratos vegetais na germinação e crescimento inicial do tomateiro. Enciclopédia biosfera, Centro Científico Conhecer, v.14 n.25; p. 2017. 10.18677/EnciBio_2017A3

MAGUIRE, J. D. Speed of germination-aid in selection and evaluation for seedling emergence and vigor. Crop Science, v. 2, p. 176-177, 1962 10.2135/cropsci1962.0011183X000200020033x

MIRANDA, C. A. S. F.; CARDOSO, M. G.; CARVALHO, M. L. M.; MACHADO, S. M. F.; GOMES, M. S.; ANDRADE, J.; TEIXEIRA, M. L. Allelopathic activity of medicinal plant essential oils on seed germination and vigor of lettuce achenes. Ciências Agrárias, v.36, p.1783-1798, 2015. 10.5433/1679-0359.2015v36n3Supl1p1783

NARIAI, M. A.; BIDO, G. S.; ZONETTI, P. C. Ação alelopática do extrato aquoso de babosa (Aloe vera L.) e hortelã (Mentha sp.) sobre a alface (Lactuca sativa L.). Revista em Agronegócios e Meio Ambiente, v.6, n.2, p. $337-$ 347, 2013.

PETROVA, S. T.; VALCHEVA, E. G.; VELCHEVA, I. G. A Case Study of Allelopathic Effect on Weeds in Wheat. Ecologia balkanica, v. 7, p. 121-129, 2015.

PINHEIRO, P. R.; SEVERIANO, R. L.; ABRÃO, C. F.; PEREIRA, M. D. Germinação e desenvolvimento inicial de plântulas de alface submetidas a extratos de pimentas. Revista Agrarian, v.9, n.32, p. 143-148, 2016.

PIRES, N. M.; OLIVEIRA, V. R. Alelopatia. In: OLIVEIRA JR., R. S.; CONSTANTIN, J.; INOUE, M. H. (Eds.) Biologia e manejo de plantas daninhas. Curitiba: Omnipax Editora, 2011. cap.5, p.95-124

RAZAVI, S. M. Plant Coumarins as Allelopathic Agents. International Journal of Biological Chemistry, v. 5, n.1: 8690, 2011. 10.3923/ijbc.2011.86.90

R CORE TEAM. R: A language and environment for statistical computing. R Foundation for Statistical Computing, Vienna, Austria. 2019. Disponível em: https://www.Rproject.org/. Acessado em: 02 jan. 2019.

ROSADO, L. D. S.; RODRIGUES, H. C. A.; PINTO, J. E. B. P.; CUSTÓDIO, T. N.; PINTO, L. B. B.; BERTOLUCCI, S. K. V. Alelopatia do extrato aquoso e do óleo essencial de folhas do manjericão "Maria Bonita" na germinação de alface, tomate e melissa. Revista Brasileira de Plantas Medicinais, v.11, n.4, p.422-428, 2009. 10.1590/S1516$\underline{05722009000400010}$

SANTOS, P. L.; PRANDO, M. B.; MORANDO, R.; PEREIRA, G. V. N.; KRONKA, A. Z. Utilização de extratos vegetais em proteção de plantas. Enciclopédia Biosfera, v.9, n.17; p. 2562, 2013.

SILVA, J. E. N.; MELHORANÇA FILHO, A. L.; ARAÚJO, M. L.; SILVA, R. G. P. O. Efeito alelopático de Piper hispidinervium sobre desenvolvimento inicial de milho (Zea mays). Revista Agrarian, v.6, n.20, p.148-153, 2013.

SILVA, V. S.; CÂNDICO, A. C. S.; MULLER, C. et al. Potencial Fitotóxico de Dicranopteris flexuosa (Schrad.) Underw. (Gleicheniaceae), Acta Botanica Brasilica, v. 25, n.1, p. 95-104. 2011. 10.1590/S0102-33062011000100012

TONETTE NETO, A.; ROJAS SERVANTES, R. P.; BONACINA, C.; CRUZ, R. M. S.; SOUZA, S. G. H. Alelopatia do óleo essencial de alfavaca em sementes de capim-braquiária. Scientia Agraria Paranaensis, v.17, n. 3, p.332-339, 2018. 